\title{
Tolerance to Hypercarbia Is Repeatable and Related to a Component of the Metabolic Phenotype in a Freshwater Fish
}

\author{
Caleb T. Hasler \\ Ian A. Bouyoucos \\ Cory D. Suski \\ Department of Natural Resources and Environmental Science, \\ University of Illinois at Urbana-Champaign, 1102 South \\ Goodwin Avenue, Urbana, Illinois 61801
}

Accepted 4/21/2017; Electronically Published 7/14/2017

\begin{abstract}
Freshwater fish may be exposed to high levels of carbon dioxide $\left(\mathrm{CO}_{2}\right)$ because of several actions, including anesthesia and high levels of aquatic respiration and potentially as the result of using high- $\mathrm{CO}_{2}$ plumes as a barrier to the movements of invasive fishes. Metabolic phenotype can potentially drive how freshwater fish respond to high $\mathrm{CO}_{2}$. We therefore quantified how tolerance (measured using time to equilibrium loss [ELT]) was driven by metabolic phenotype in a cosmopolitan freshwater fish species, Micropterus salmoides. ELT was repeatable, with $60 \%$ of the variance across trials attributable to individual differences. For each fish, standard metabolic rate and maximum metabolic rate were measured using respirometers and time to exhaustion after a chase test was recorded. Fish with high anaerobic performance were less tolerant to elevated $\mathrm{CO}_{2}$, potentially as a result of preexisting metabolic acidosis. Standard metabolic rate and aerobic scope did not predict ELT. Our findings define which fish may be more vulnerable to high $\mathrm{CO}_{2}$, a potential mechanism for this tolerance, and show that tolerance to high $\mathrm{CO}_{2}$ may be acted on by natural selection. Should freshwater ecosystems become elevated in $\mathrm{CO}_{2}$, by either natural means or anthropogenic means, it is possible that there is potential for heritable selection of $\mathrm{CO}_{2}$ tolerance, evidenced by the fact that ELT was found to be repeatable.
\end{abstract}

Keywords: acidification, anaerobic activity, aerobic scope, equilibrium loss.

${ }^{*}$ Corresponding author. Present address: Department of Biology, University of Winnipeg, 515 Portage Avenue, Winnipeg, Manitoba R3B 2E9, Canada; e-mail: c.hasler@uwinnipeg.ca.

Physiological and Biochemical Zoology 90(5):583-587. 2017. (C) 2017 by The University of Chicago. All rights reserved. 1522-2152/2017/9005-7015 $\$ 15.00$. DOI: $10.1086 / 693376$

\section{Introduction}

The past century has seen a rise in the amount of carbon dioxide $\left(\mathrm{CO}_{2}\right)$ in the atmosphere, along with a concomitant rise in the partial pressure of $\mathrm{CO}_{2}\left(\mathrm{PCO}_{2}\right)$ in marine, and potentially freshwater, ecosystems (Hasler et al. 2016; McNeil and Sasse 2016). Research has demonstrated negative outcomes for aquatic taxa to elevated $\mathrm{PCO}_{2}$, particularly in marine fishes (Kroeker et al. 2013; Heuer and Grosell 2014). However, freshwater fishes are much more likely to experience high environmental $\mathrm{PcO}_{2}$ from actions such as anesthesia (Mitsuda et al. 1980; Marking and Meyer 1985), crowding at aquaculture facilities (e.g., Santos et al. 2013), and potential deployment of high- $\mathrm{CO}_{2}$ plumes to control the movements of invasive fishes (Noatch and Suski 2012; Donaldson et al. 2016; Cupp et al. 2017). Currently, a potential $\mathrm{CO}_{2}$ plume that would be approximately 50-100 times the $\mathrm{CO}_{2}$ of surrounding waters has been reviewed for the Illinois River to control the movements of bigheaded carp (Hypophthalmichthys spp.; US Army Corps of Engineers 2014).

Freshwater fishes respond negatively to elevated $\mathrm{PcO}_{2}$ and show high individual variation in the magnitude of their behavioral and physiological responses. For example, shuttling away from elevated $\mathrm{PCO}_{2}$ of three freshwater species showed considerable within-species variation (threefold difference between minimum and maximum shuttling $\mathrm{PCO}_{2}$; Kates et al. 2012) despite $\mathrm{PCO}_{2}$ levels being found to cause a range of negative physiological responses (Dennis et al. 2015). To assess within-species variation, determining the repeatability of a response to elevated $\mathrm{PCO}_{2}$ is necessary, which specifically requires quantifying the proportion of the total variation among measurements within individuals (Wolak et al. 2012). Once within-species variation for a response to elevated $\mathrm{PCO}_{2}$ is measured, the mechanisms responsible for within-species variation to high $\mathrm{PCO}_{2}$ can be determined and used to assess vulnerabilities of freshwater fisheries to environmental change (Seebacher and Franklin 2012), including the potential deployment of high- $\mathrm{CO}_{2}$ plumes (Noatch and Suski 2012).

A potential mechanism for the responses of freshwater fishes to elevated $\mathrm{PCO}_{2}$ may involve metabolic phenotype, which is composed of standard metabolic rate (SMR), maximum metabolic rate (MMR), aerobic scope (AS), and anaerobic activity (Metcalfe et al. 2016). Metabolic phenotype demonstrates intraspecific variation (Burton et al. 2011) and has also been shown to drive both performance and behavioral responses to changes in environmental conditions for fishes, making it relevant to use in studies focused on environmental factors (Claireaux and Lefrancois 2007; Metcalfe et al. 2016). More importantly, aspects of an individual's metabolic phenotype can be affected by ambient levels of $\mathrm{PCO}_{2}$, 
potentially driving within-species variation in tolerance. For example, high ambient $\mathrm{PCO}_{2}$ can reduce both metabolic rate and aerobic swimming performance in fish (Basu 1959; Dahlberg et al. 1968), and anaerobic activity may predict tolerance to high $\mathrm{PCO}_{2}$, as the ability to withstand metabolic acidosis resulting from exhaustive exercise may lead to a similar capability to endure $\mathrm{CO}_{2}^{-}$ induced respiratory acidosis (Wood 1991). Together, several aspects of an individual's metabolic phenotype may predict tolerance and performance of fish in areas of elevated $\mathrm{PCO}_{2}$.

The objectives of this study were to define whether physiological tolerance to high $\mathrm{PCO}_{2}$ in a freshwater fish (largemouth bass [LMB] Micropterus salmoides Lacépéde) is a repeatable trait and whether tolerance was predicted by metabolic phenotype. Trait repeatability is important because it suggests heritability, and thus there is potential for natural selection to act on the trait (Killen et al. 2016). We chose to use time to equilibrium loss (ELT) as a metric of tolerance because it is easily measured and occurs before death, and fish exposed to high $\mathrm{PCO}_{2}$ can still recover if placed in freshwater with low $\mathrm{PcO}_{2}$ following equilibrium loss (Yoshikawa et al. 1994). Given that within-species variation has been found in several behavioral and physiological responses to elevated $\mathrm{PCO}_{2}$, we predicted that tolerance to elevated $\mathrm{PCO}_{2}$ would be repeatable. Further, because metabolic rates are influenced by exposure to elevated $\mathrm{PCO}_{2}$, we predicted that at least part of the metabolic phenotype, if not the entire metabolic phenotype, would influence tolerance.

\section{Material and Methods}

Twenty-five hatchery-reared subadult LMB $(181 \pm 12 \mathrm{~mm}$ total length, mean $\pm \mathrm{SD} ; 81.6 \pm 16.6$ g mass) were held at $19.8^{\circ} \pm$ $0.4^{\circ} \mathrm{C}$ for $2 \mathrm{wk}$ before the experiments in one of two tanks. For each fish, four experiments were conducted over four consecutive days. First, fish underwent intermittent-flow respirometry to measure SMR (Chabot et al. 2016), MMR (Norin and Clark 2016), and AS (MMR-SMR). SMR was measured overnight on the first day and was calculated using the mean lowest normal distribution method (Chabot et al. 2016). On the second day following completion of the SMR measurements, fish were chased to exhaustion using tail pinching and air exposed for $3 \mathrm{~min}$ before being transferred to respirometers for at least three metabolic rate measurement cycles to determine MMR. Following MMR measurements, fish were given $24 \mathrm{~h}$ to recover from MMR assessment (Gustaveson et al. 1991) and then on the third day exposed to high $\mathrm{PCO}_{2}$ to quantify trait tolerance. Tolerance to high $\mathrm{PCO}_{2}$ was measured by exposing fish, individually, in a 15-L cooler to $174,, 000 \pm 2,, 000 \mu \mathrm{atm}$ of $\mathrm{PcO}_{2}$ and measuring ELT (for comparative purposes, $174,000 \mu \mathrm{atm}$ is equal to $17.63 \mathrm{kPa}$ or $132.24 \mathrm{mmHg}$ ). The target partial pressure was chosen as it has previously been shown to induce physiological changes in freshwater fishes, including equilibrium loss (Mitsuda et al. 1980; Yoshikawa et al. 1991, 1994), and should not compromise the cardiorespiratory system because of hemoglobin denaturing (Manwell et al. 1963). On the fourth day, after $24 \mathrm{~h}$ had elapsed from the first tolerance test, fish were subjected to the same conditions to measure a second ELT to define repeatability of this response. ELT was tested twice to limit the potential for prolonged fish holding, habituation, learning, and fasting to potentially influence ELT (Tierney 2016). All fish were fasted for $24 \mathrm{~h}$ before the commencement of the metabolic rate determination and were not fed until after the second tolerance test (i.e., each fish was fasted for a total of $5 \mathrm{~d}$ ).

Mass-specific rates of oxygen consumption $\left(\dot{\mathrm{MO}}_{2} ; \mathrm{mg} \mathrm{O}_{2} \mathrm{~kg}^{-1} \mathrm{~h}^{-1}\right)$ were measured in $740-\mathrm{mL}$ resting respirometry chambers $(6.2-$ 14.8 times animal volume; $9.7 \pm 2.4$; four chambers were used throughout the study). Automated measurement cycles consisted of a 4-min open/flush period, a 1-min closed/wait period, and a 5-min closed/measure period (Svendsen et al. 2016). Dissolved oxygen levels, on average, declined to $88.1 \% \pm 9.0 \%$ of fully saturated freshwater $\left(9.09 \mathrm{mg} \mathrm{L}^{-1}\right.$ at $\left.20^{\circ} \mathrm{C}\right)$ during measure periods. To account for background respiration, a single oxygen consumption measurement was taken in sealed chambers without fish before SMR measurement and after MMR measurement (Rodgers et al. 2016). Background respiration was negligible if coefficients of determination for rates of oxygen consumption were less than 0.95 (Svendsen et al. 2016). If background respiration values were considerable, a linear increase in background $\mathrm{MO}_{2}$ was assumed, and values for background respiration were subtracted from each $\dot{\mathrm{MO}}_{2}$ measurement using the linear equation generated for background $\dot{\mathrm{MO}}_{2}$ against time (Rodgers et al. 2016).

The repeatability of ELT following two exposures to elevated $\mathrm{PCO}_{2}$ was quantified using the intraclass correlation coefficient (ICC) using the ICC package in R (Lessells and Boag 1987; Cicchetti 1994; Wolak et al. 2012). The influence of aerobic (SMR and AS) and anaerobic (time to exhaustion) metrics on ELT was assessed using a linear mixed-effects (LME) model with a Gaussian error distribution. Fish mass was included as a covariate, and tank of origin and fish ID were included as random effects. The LME was constructed using the "lme4" package in R (Bates 2010). The importance of fixed effects was determined by generating credible intervals from 1,000 posterior simulations of each fixed effect using the "sim" function in the "arm" package in R (Bates et al. 2015; Gelman and Su 2016). Credible intervals that did not over-

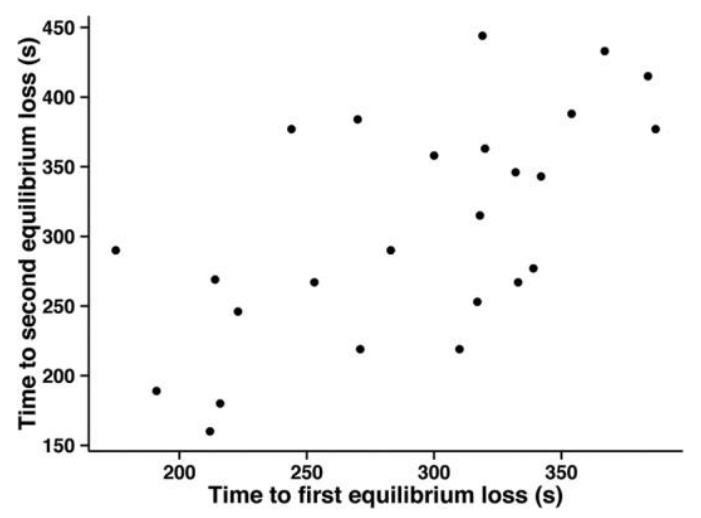

Figure 1. Time to equilibrium loss (s) during exposure to two trials of high carbon dioxide partial pressure. Repeatability $=0.60$. Each data point represents one largemouth bass. 


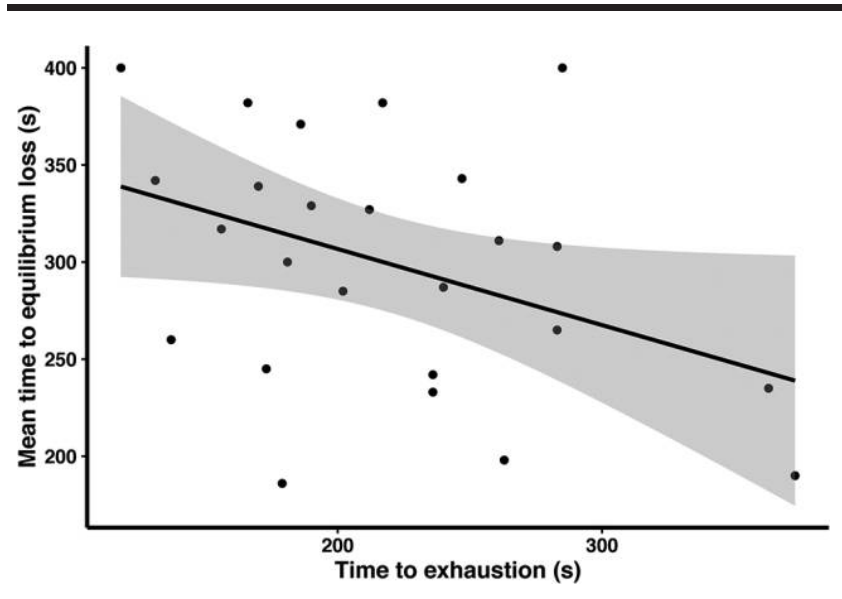

Figure 2. Relationship between time to equilibrium loss (s) and time to exhaustion for largemouth bass. Regression line is $y=385.11+(-0.39 x)$, $\left.r^{2}=0.16\right)$. The shaded area represents the $95 \%$ confidence interval of the regression line. Each data point represents the mean time to equilibrium loss for one individual fish over two trials.

lap zero at the $95 \%$ level were considered significant. Nonsignificant variables were retained in the full model to control for the effects of body mass and to obtain relative parameter estimates. A Pearson-fitted residual-fit plot was inspected and found to satisfy model assumptions (i.e., the model was validated).

\section{Results}

ELT after hatchery-reared fish were placed in a bath of high $\mathrm{PCO}_{2}$ demonstrated a twofold difference between the lowest and highest values (fig. 1) and tended to show strong repeatability, as $60 \%$ of the variance in the data set was attributable to consistent differences among individuals between trials (ICC $=0.60,95 \%$ confidence interval [CI] 0.29-0.80). Fish that had longer exhaustion time following anaerobic swimming had marginally shorter ELT after being placed in a bath of high $\mathrm{PCO}_{2}$ (fig. 2; table 1). SMR, AS, and mass were not found to predict ELT (table 1).

\section{Discussion}

ELT is often used by biologists as a diagnostic tool to define physiological tolerances of animals to environmental variables (Gibert et al. 2001). Equilibrium loss in fish exposed to high $\mathrm{PCO}_{2}$ likely occurs because of a lowering of brain $\mathrm{pH}$ when environmental $\mathrm{CO}_{2}$ enters the bloodstream of the fish and crosses the blood-brain barrier, which induces loss of motor function and anesthesia (Mitsuda et al. 1980; Yoshikawa et al. 1994). More importantly, situations that result in loss of equilibrium may ultimately lead to mortality (Raby et al. 2015); therefore, within populations, some individuals may be more vulnerable to the physiological and behavioral changes previously found in fishes exposed to high $\mathrm{PcO}_{2}$ (Clements and Hunt 2015). Hatcheryreared $\mathrm{LMB}$ exposed to high $\mathrm{PCO}_{2}$ exhibited repeatability for ELT, suggesting that interindividual tolerance to high $\mathrm{PCO}_{2}$ in freshwater fish is a stable response that could then be influenced by natural selection (Killen et al. 2016). Should responses to high $\mathrm{PCO}_{2}$ be adaptive and linked to fitness, fish populations may become more tolerant to prolonged periods of high $\mathrm{PcO}_{2}$.

Fish that had longer exhaustion time following anaerobic swimming had shorter ELT after being placed in a bath of high $\mathrm{PcO}_{2}$. This relationship, however, was only marginally significant ( $95 \%$ credible interval, -0.75 to -0.01 ) and therefore potentially coincidental. Exhaustive exercise endpoints are often subjective, and if changes in levels of biomarkers of anaerobic metabolism (e.g., muscle lactate dehydrogenase activity, blood lactate levels, and pH; Kieffer 2000) are not quantified, exhaustion, as defined by this study, may not be indicative of true physiological exhaustion (Norin and Clark 2016). Furthermore, time to exhaustion observed in LMB may have been a behavioral response to anaerobic metabolism or fish lacking motivation to swim (Peake and Farrell 2006). Conversely, the respiratory acidosis induced by external $\mathrm{PCO}_{2}$ from the $\mathrm{CO}_{2}$ bath may have exacerbated a metabolic acidosis caused by chasing (Wood 1991), though it is unlikely that chasing resulted in an acidosis that persisted 24 or even $48 \mathrm{~h}$ postexercise when fish were exposed to high $\mathrm{Pco}_{2}$ (Milligan 1996). Additionally, the water source used in the holding tanks is considered to be hard on the basis of geographic location; therefore, compensation of respiratory acidosis should not have been hindered by holding conditions (Larsen and Jensen 1997). Thus, time to exhaustion had a negative relationship with $\mathrm{CO}_{2}$ tolerance, though it is unclear whether this result occurred by happenstance or whether it is indicative of an unexplained mechanism.

The aerobic components of the metabolic phenotype (i.e., $\mathrm{SMR}$ and AS) did not influence tolerance to high $\mathrm{PCO}_{2}$. Increased costs of acid-base regulation from exposure to $\mathrm{CO}_{2}$ should be reflected in SMR, and AS would be expected to predict capacity for managing respiratory acidosis, which could improve tolerance (Pörtner and Langenbuch 2005). However, $\mathrm{PCO}_{2}$ used for this study was high in comparison to future projections of freshwater $\mathrm{PCO}_{2}$ (Hasler et al. 2016), and acid-base compensation (e.g., increased net $\mathrm{HCO}_{3}^{-} / \mathrm{Cl}^{-}$exchange; Brauner and Baker 2009) may not have been possible during acute exposure. Furthermore, the inability of $\mathrm{pH}$ buffering systems to resolve the hypercarbiainduced respiratory acidosis would support an inevitable drop

Table 1: Measured values and output of linear mixed-effects model for metabolic trait predictors on time to equilibrium loss following exposure to high carbon dioxide partial pressure

\begin{tabular}{|c|c|c|c|}
\hline Term & $\begin{array}{l}\text { Measured value } \\
(\text { mean } \pm \text { SD) }\end{array}$ & $\begin{array}{c}\text { Mean } \\
\text { estimate/change } \\
\text { in intercept }\end{array}$ & $\begin{array}{l}\text { Credible } \\
\text { interval }\end{array}$ \\
\hline Intercept & NA & 528.79 & 213.29 to 816.42 \\
\hline SMR & $117.40 \pm 12.08$ & -1.21 & -3.58 to .93 \\
\hline AS & $150.26 \pm 38.26$ & -.22 & -.86 to .51 \\
\hline Exhaust & $219.52 \pm 65.76$ & -.39 & -.75 to -.01 \\
\hline Mass (g) & $80.24 \pm 20.90$ & .37 & -.85 to 1.62 \\
\hline
\end{tabular}

Note. SMR = standard metabolic rate $\left(\mathrm{mg} \mathrm{O}_{2} \mathrm{~kg}^{-1} \mathrm{~h}^{-1}\right)$; AS = aerobic scope $\left(\mathrm{mg} \mathrm{O}_{2} \mathrm{~kg}^{-1} \mathrm{~h}^{-1}\right)$; exhaust $=$ time to exhaustion $(\mathrm{s})$. Terms in bold denote statistical significance. $\mathrm{NA}=$ not applicable. 
in brain $\mathrm{pH}$, ultimately resulting in equilibrium loss (Yoshikawa et al. 1994). Though it is uncertain whether aerobic capacity would be altered during acute or chronic exposure to moderate or low $\mathrm{PcO}_{2}$ (Couturier et al. 2013), the absence of observed relationships between SMR and AS with $\mathrm{CO}_{2}$ tolerance reflects a lack of understanding of how high $\mathrm{PCO}_{2}$ influences fish.

In conclusion, tolerance to high $\mathrm{PcO}_{2}$ in a freshwater fish was found to be repeatable and predicted by a fish's capacity for anaerobic activity. These findings indicate that fish exposed to high $\mathrm{PCO}_{2}$, either because of environmental change or as a result of the use of $\mathrm{CO}_{2}$ plumes to limit the distribution of invasive species, may demonstrate a repeatable variation in reactions to this $\mathrm{CO}_{2}$ exposure, which ultimately may be heritable and therefore influenced by natural selection. Future studies should aim to understand the potential for responses to $\mathrm{CO}_{2}$ to be repeatable and the likelihood that they are influenced by natural selection. Other measurements of tolerance, including behavioral avoidance and the potential for interactive effects with other environmental stressors, might also be assessed and related to tolerance to high $\mathrm{PCO}_{2}$.

\section{Acknowledgments}

E. Schneider helped with fish care. All procedures were approved by the University of Illinois Institutional Animal Care and Use Committee (protocol 15137). The authors declare no competing interests. C.T.H., I.A.B., and C.D.S. conceived the study, analyzed the data, and drafted the manuscript; C.T.H. and I.A.B. undertook the experiments. The study was supported by Illinois Department of Natural Resources (CAFWS-93) and the US Geological Survey, through funds provided to C.D.S. by the Great Lakes Restoration Initiative (G14AC00119).

\section{Literature Cited}

Basu S.P. 1959. Active respiration of fish in relation to ambient concentrations of oxygen and carbon dioxide. LFish Res Board Can 16:175-212.

Bates D. 2010. lme4: mixed-effects modeling with R. Springer, Berlin.

Bates D., M. Mächler, B.M. Bolker, and S.C. Walker. 2015. Fitting linear mixed-effects models using lme4. L Stat Softw 67:1-48.

Brauner C.J. and D.W. Baker. 2009. Patterns of acid-base regulation during exposure to hypercarbia in fishes. Pp. 43-63 in M.L. Glass and S.C. Wood, eds. Cardio-respiratory control in vertebrates. Springer, Berlin.

Burton T., S.S. Killen, J.D. Armstrong, and N.B. Metcalfe. 2011. What causes intraspecific variation in resting metabolic rate and what are its ecological consequences? Proc R Soc B 278:3465-3473.

Chabot D., J.F. Steffensen, and A.P. Farrell. 2016. The determination of standard metabolic rate in fishes. LFish Biol 88:81-121.

Cicchetti D.V. 1994. Guidelines, criteria, and rules of thumb for evaluating normed and standardized assessment instruments in psychology. Psychol Assess 6:284-290.
Claireaux G. and C. Lefrancois. 2007. Linking environmental variability and fish performance: integration through the concept of scope for activity. Philos Trans R Soc B 362:20312041.

Clements J.C. and H.L. Hunt. 2015. Marine animal behaviour in a high $\mathrm{CO}_{2}$ ocean. Mar Ecol Prog Ser 536:259-279.

Couturier C.S., J.A. Stecyk, J.L. Rummer, P.L. Munday, and G.E. Nilsson. 2013. Species-specific effects of near-future $\mathrm{CO}_{2}$ on the respiratory performance of two tropical prey fish and their predator. Comp Biochem Physiol A 166:482-489.

Cupp A.R., R.A. Erickson, K.T. Fredricks, N.M. Swyers, T.W. Hatton, and J.J. Amberg. 2017. Responses of invasive silver and bighead carp to a carbon dioxide barrier in outdoor ponds. Can I Fish Aquat Sci 305:297-305.

Dahlberg M.L., D.L. Shumway, and P. Doudoroff. 1968. Influence of dissolved oxygen and carbon dioxide on swimming performance of largemouth bass and coho salmon. L Fish Res Board Can 25:49-70.

Dennis C.E., S. Adhikari, and C.D. Suski. 2015. Molecular and behavioral responses of early-life stage fishes to elevated carbon dioxide. Biol Invasions 17:3133-3151.

Donaldson M.R., J.J. Amberg, S. Adhikari, A. Cupp, N.R. Jensen, J. Romine, A. Wright, et al. 2016. Carbon dioxide as a tool to deter the movement of invasive bigheaded carps. Trans Am Fish Soc 145:657-670.

US Army Corps of Engineers. 2014. The GLMRIS Report. http:// glmris.anl.gov/glmris-report/.

Gelman A. and Y.-S. Su. 2016. arm: data analysis using regression and multilevel/hierarchical models. R package, version 1.9-1. https://CRAN.R-project.org/package $=$ arm.

Gibert P., B. Moreteau, G. Pétavy, D. Karan, and J.R. David. 2001. Chill-coma tolerance, a major climatic adaptation among Drosophila species. Evolution 55:1063-1068.

Gustaveson A.W., R.S. Wydoski, and G.A. Wedemeyer. 1991. Physiological response of largemouth bass to angling stress. Trans Am Fish Soc 120:629-636.

Hasler C.T., D. Butman, J.D. Jeffrey, and C.D. Suski. 2016. Freshwater biota and rising $\mathrm{pCO}_{2}$. Ecol Lett 19:98-108.

Heuer R.M. and M. Grosell. 2014. Physiological impacts of elevated carbon dioxide and ocean acidification on fish. Am J Physiol 307:R1061-R1084.

Kates D., C. Dennis, M.R. Noatch, and C.D. Suski. 2012. Responses of native and invasive fishes to carbon dioxide: potential for a nonphysical barrier to fish dispersal. Can I Fish Aquat Sci 69:1748-1759.

Kieffer J.D. 2000. Limits to exhaustive exercise in fish. Comp Biochem Physiol A 126:161-179.

Killen S.S., B. Adriaenssens, S. Marras, G. Claireaux, and S.J. Cooke. 2016. Context dependency of trait repeatability and its relevance for management and conservation of fish populations. Conserv Physiol 4:cow007. doi:10.1093/conphys /cow007.

Kroeker K.J., R.L. Kordas, R. Crim, I.E. Hendriks, L. Ramajo, G.S. Singh, C.M. Duarte, et al. 2013. Impacts of ocean acidification on marine organisms: quantifying sensitivities and interaction with warming. Glob Chang Biol 19:1884-1896. 
Larsen B.K. and F.B. Jensen. 1997. Influence of ionic composition on acid-base regulation in rainbow trout (Oncorhynchus mykiss) exposed to environmental hypercapnia. Fish Physiol Biochem 16:157-170.

Lessells C.M. and P.T. Boag. 1987. Unrepeatable repeatabilities: a common mistake. Auk 104:116-121.

Manwell C., C.M.A. Baker, and W. Chillders. 1963. The genetics of hemoglobin in hybrids. I. A molecular basis for hybrid vigor. Comp Biochem Physiol 10:103-120.

Marking L.L. and F.P. Meyer. 1985. Are better anesthetics needed in fisheries? Fisheries 10:2-5.

McNeil B.I. and T.P. Sasse. 2016. Future ocean hypercapnia driven by anthropogenic amplification of the natural $\mathrm{CO}_{2}$ cycle. $\mathrm{Na}$ ture 529:383-386.

Metcalfe N.B., T.E. Van Leeuwen, and S.S. Killen. 2016. Does individual variation in metabolic phenotype predict fish behaviour and performance? LFish Biol 88:298-321.

Milligan C.L. 1996. Metabolic recovery from exhaustive exercise in rainbow trout. Comp Biochem Physiol 113A:51-60.

Mitsuda H., K. Nakajima, H. Mizuno, F. Kawai, and A. Yamamoto. 1980. Effects of carbon dioxide on carp. L Nutr Sci Vitaminol 26:99-102.

Noatch M.R. and C.D. Suski. 2012. Non-physical barriers to deter fish movements. Environ Rev 20:1-12.

Norin T. and T.D. Clark. 2016. Measurement and relevance of maximum metabolic rate in fishes. LFish Biol 88:122-151.

Peake S.J. and A.P. Farrell. 2006. Fatigue is a behavioural response in respirometer-confined smallmouth bass. L Fish Biol 68: $1742-1755$.

Pörtner H.O. and M. Langenbuch. 2005. Synergistic effects of temperature extremes, hypoxia, and increases in $\mathrm{CO}_{2}$ on marine animals: from earth history to global change. J Geophys Res 110. doi:10.1029/2004JC002561.
Raby G.D., S.G. Hinch, D.A. Patterson, J.A. Hills, L.A. Thompson, and S.J. Cooke. 2015. Mechanisms to explain purse seine bycatch mortality of coho salmon. Ecol Appl 25:1757-1775.

Rodgers G.G., P. Tenzing, and T.D. Clark. 2016. Experimental methods in aquatic respirometry: the importance of mixing devices and accounting for background respiration. L Fish Biol 88:65-80.

Santos G.A., J.W. Schrama, J. Capelle, J.H.W.M. Rombout, and J.A.J. Verreth. 2013. Effects of dissolved carbon dioxide on energy metabolism and stress responses in European seabass (Dicentrarchus labrax). Aquac Res 44:1370-1382.

Seebacher F. and C.E. Franklin. 2012. Determining environmental causes of biological effects: the need for a mechanistic physiological dimension in conservation biology. Philos Trans R Soc B 367:1607-1614.

Svendsen M.B., P.G. Bushnell, and J.F. Steffensen. 2016. Design and setup of intermittent-flow respirometry system for aquatic organisms. L Fish Biol 88:26-50.

Tierney K.B. 2016. Chemical avoidance responses of fishes. Aquat Toxicol 174:228-241.

Wolak M.E., D.J. Fairbairn, and Y.R. Paulsen. 2012. Guidelines for estimating repeatability. Methods Ecol Evol 3:129137.

Wood C.M. 1991. Acid-base and ion balance, metabolism, and their interaction, after exhaustive exercise in fish. J Exp Biol 160:285-308.

Yoshikawa H., F. Kawai, and M. Kanamori. 1994. The relationship between the EEG and brain $\mathrm{pH}$ in carp, Cyprinus carpio, subjected to environmental hypercapnia at an anesthetic level. Comp Biochem Physiol 107:307-312.

Yoshikawa H., S. Yokoyama, S. Ueno, and H. Mitsuda. 1991. Changes of blood gas in carp, Cyprinus carpio anesthetized with carbon dioxide. Comp Biochem Physiol 98:431-436. 